\title{
Myocarditis, CTCAE 5.0
}

National Cancer Institute

\section{Source}

National Cancer Institute. Myocarditis, CT CAE 5.0. NCI Thesaurus. Code C146695.

A disorder characterized by inflammation of the muscle tissue of the heart. 